\title{
Predictors of return to work following motor vehicle related orthopaedic trauma
}

\author{
Darnel F. Murgatroyd ${ }^{1 *}$, lan A. Harris ${ }^{2,3,4}$, Yvonne $\operatorname{Tran}^{1}$ and lan D. Cameron ${ }^{1}$
}

\begin{abstract}
Background: Work disability following motor vehicle related orthopaedic trauma is a significant contributor to the burden of injury and disease. Early identification of predictors for return to work (RTW) is essential for developing effective interventions to prevent work disability. The study aim was to determine the predictors (including compensation related factors) of time to RTW following motor vehicle related orthopaedic trauma.

Methods: Admitted patients were recruited prospectively from two trauma hospitals with upper and/or lower extremity fractures following a motor vehicle crash. Baseline and follow up data were collected by written questionnaire. For baseline, this occurred in person within 2 weeks of injury. For follow up, this occurred by mail at six, 12 and 24 months. Additional demographic and injury-related information was retrieved from hospital databases. Analysis involved: descriptive statistics; logrank test to detect survival distributions of categorical variables; and Cox proportional hazards regression models for risks of time to RTW using baseline characteristic and compensation related variables (at 6 months).

Results: Of 452 study participants 334 (74\%) were working pre-injury: results are based on this subset. Baseline characteristics were mean age 36 years (13.9 Standard Deviation [SD]), $80 \%$ male; $72 \%$ self-assessed very goodexcellent pre-injury health, $83 \%$ household income $>$ AU\$40,000 (Australian Dollar). Follow up data was available for $233(70 \%), 210$ (63\%), and 182 (54\%) participants at six, 12 and 24 months respectively.

Significant risks of a longer time to RTW were greater injury severity, as measured by the New Injury Severity Score (NISS) (Hazards Rate Ratio [HRR] = 0.54, $95 \%$ Cl 0.35-0.82); and lower occupational skill levels (HRR =0.53, $95 \% \mathrm{Cl}$ 0.34-0.83). Significant risks of a shorter time to RTW were: recovery expectations for usual activities within 90 days $(\mathrm{HRR}=2.10,95 \% \mathrm{Cl}$ 1.49-2.95); full-time pre-injury work hours ( $\mathrm{HRR}=1.99,95 \% \mathrm{Cl} 1.26-3.14)$; and very good self-assessed pre-injury health status (HRR $=1.41,95 \% \mathrm{Cl}$ 0.98-2.02). Legal representation (analysed at six months only) was not associated with time to RTW. At each time period, there were 146 (63\%), 149 (71\%), and 137 (76\%) working participants.

Conclusions: A longer time to RTW was associated with greater injury severity and lower occupational skill levels; while a shorter time to RTW was associated with recovery expectations for usual activities within 90 days, full-time pre-injury work hours, and very good self-assessed pre-injury health status. Our findings reinforce existing research. There is an opportunity to trial interventions that address potentially modifiable factors. The issues surrounding legal representation are complex and require further research.
\end{abstract}

Keywords: Compensation and redress, Wounds and injury, Multiple trauma, Return to work

\footnotetext{
* Correspondence: dmur0062@uni.sydney.edu.au

'John Walsh Centre for Rehabilitation Research, The University of Sydney,

Kolling Institute, Sydney, NSW, Australia

Full list of author information is available at the end of the article
} 


\section{Background}

Work is pivotal to determining individual identity, social roles and status; it is also a key factor in physical and mental health; and it provides financial security and enables active participation in society [1]. Consequently, work disability following trauma intensifies the societal burden with increased disability, pain and health care utilisation rates [2-4]. In addition, motor vehicle related orthopaedic trauma is a significant contributor to the burden of injury and disease that commonly involves people of working age [5].

Early identification of predictors for return to work (RTW) after injury is essential as a prerequisite for developing effective interventions to prevent work disability and reduce the overall burden of injury [6]. However, there remains a lack of rigorous prospective studies following orthopaedic trauma that investigate these predictors. Results from a systematic review were inconclusive with limited predictors measured across studies, short follow up periods, and selective reporting of results [7]. Nonetheless, individual studies have shown that education, occupation, injury severity, self-efficacy and compensation related factors are predictive of work disability in this population [2-4, 8].

There are many predictors for RTW: individual worker factors such as job and injury characteristics; medical and vocational rehabilitation interventions; and organisational employer/insurer characteristics [6, 9]. Other factors include societal, legislative and macro-economic factors such as litigation, compensation scheme design, wage replacement benefits, and unemployment rates. Many of these are population specific [6].

In that context, there is evidence of an association between compensation related factors and poorer health outcomes, including RTW, following trauma [7, 10]. These associations have been found in workers compensation and traffic injury compensation systems across jurisdictions and injury types, despite the highly contextual sociopolitical environment in which compensation schemes operate. Similarly in qualitative research, adversarial claims processes, perceived illegitimacy of injury, and financial hardship have also impacted negatively on injury recovery and RTW [11-13].

Our study explored the association between individual worker and injury characteristics, compensation related factors, and time to RTW. Of particular interest were predictors that could be amenable to change $[6,7]$. Thus, the aim was to determine the predictors (including compensation related factors) of time to RTW following motor vehicle related orthopaedic trauma.

\section{Methods}

\section{Study design and setting}

The inception cohort study recruited patients from two trauma hospitals in Sydney, New South Wales (NSW),
Australia between November 2007 and February 2011, to provide a representative sample of motor vehicle related orthopaedic trauma requiring inpatient hospitalisation. Eligible patients identified via a hospital trauma database were invited to participate. Informed consent was obtained. Patients from Culturally and Linguistically Diverse (CALD) backgrounds were interviewed with an English speaking family member.

Inclusion criteria were:

- admission to hospital within 2 weeks of injury;

- involvement in a motor vehicle crash;

- age 18 years or over; and

- an upper or lower extremity fracture (humerus, radius, ulna, pelvis, acetabulum, femur, patella, tibia, fibula, talus, calcaneus).

All extremity and pelvic fractures that required admission to hospital were included. These fractures were selected because treatment usually involves hospital admission and surgical intervention, but surgery alone was not an inclusion criterion. There were no restrictions, therefore, intra-articular and/or extra-articular, open and/or closed, and simple and/or complex fractures were included. Spinal trauma was excluded because these injuries were not usually treated at the participating centres.

Exclusion criteria were:

- dementia or a significant pre-existing cognitive impairment preventing the ability to consent;

- spinal cord injury;

- Glasgow Coma Score <12 on admission;

- amputation of a limb; or

- isolated clavicle, scapula, phalangeal, carpal, metacarpal, tarsal or metatarsal fractures not requiring admission to hospital.

There were 32 variables: allowing for 10 participants per variable, a sample size of 450 was calculated [14]. This was considered sufficient to accommodate a $25 \%$ loss to follow up, based on similar research [15].

Follow up questionnaires were posted at six, 12 and 24 months post injury. If no response was received by 3 weeks, up to six attempts were made to contact participants by telephone and/or by mailing additional questionnaires.

Baseline data were collected in hospital within 2 weeks of injury using a written questionnaire. Demographic and injury related information was retrieved from the hospital trauma database and records. The study factors were chosen to reflect the study aims with reference to relevant research [16-18]. The study was approved by the governing human research ethics committees (South 
Western Sydney Local Health District, South Eastern Sydney Local Health District, and The University of Sydney).

\section{Injury related factors}

Injuries were coded using the Abbreviated Injury Scale (AIS) (1990 Revision, Update 98) [19]. The AIS ranks injuries from one to six (six is not survivable). The Injury Severity Score (ISS) and New Injury Severity Score (NISS) were calculated by summing the squares of the three highest AIS scores from different body regions (ISS), and regardless of body region (NISS). They are indicators of potential mortality [20]. Injuries were classified as minor - moderate [1-8], serious [9-15] or severe - critical (16-75) [21].

\section{Socio-demographic factors}

Socio-demographic factors included age, gender, marital status, occupation, and education. Income was measured exclusive and inclusive of household structure to allow for potential differences in income distribution. An adjusted income (inclusive of household structure) was calculated by dividing the income by the sum of points: 1 for the first person aged $\geq 15$ years; 0.5 for each additional person aged $\geq 15$ years; and 0.3 for each person aged $<15$ years [22].

\section{Health related factors}

Self-reported chronic illnesses were measured as an indicator of baseline health status, they were asthma, cancer, heart and circulatory conditions, diabetes, arthritis, osteoporosis, mental and behavioural problems, and neck/back disorders. These self-reported illnesses were compatible with the National Health Priority Areas initiative (conditions that imposed high social and financial costs on Australian society) [23]. A chronic condition was defined as one which the patient currently has, and which has lasted or is expected to last for six months or more, from the Australian Bureau of Statistics (ABS) Health Survey [22, 23]. Other factors included: recent injuries (other than the motor vehicle crash) in the last 4 weeks requiring medical intervention or a decrease in usual activities; medication use in the last 2 weeks for a chronic illness; and smoker status [22].

Previous research has found an association between poor expectations for recovery and poor RTW and/or health outcomes, but there was an absence of validated measures $[9,18,24,25]$. Therefore, we used two applicable measures from a large Canadian study of soft tissue injuries [24]. The questions asked were: If you were working before the motor vehicle accident, do you think you will recover enough to return to your usual job $(\mathrm{Y} / \mathrm{N})$; and How long do you think it will take for you to return to your usual activities (number of days).
Alcohol consumption was measured using the first three questions of the Alcohol Use Disorders Identification Test: Self-Report Version (AUDIT-C) [26]. The word 'standard' and 'in the past year' were added. Risk of long/short term harm due to alcohol consumption was assessed with the National Health and Medical Research Council (NHMRC) levels [27]. Because these levels were mismatched with the AUDIT-C categories, an algorithm was used based on the Bettering the Evaluation of Care and Health (BEACH) Survey, (Associate Professor K Conigrave, personal communication March 19, 2007). Categories for other study factors are explained in the Tables.

\section{Compensation related measures}

The majority of compensation related factors were recorded at six months because most questions would have been unanswerable at baseline. The following questions were asked: claim made $(\mathrm{Y} / \mathrm{N})$; claim type (Compulsory Third Party [CTP]/Workers Compensation $[\mathrm{WC}] /$ other); claim accepted (Y/N/don't know); and legal representation obtained $(\mathrm{Y} / \mathrm{N})$. Claim made 'Yes' was defined as making a personal injury claim of any type; which included a CTP Accident Notification Form (ANF) for expenses less than AU\$5,000 (Australian Dollar) within 28 days of injury. At baseline self-reported fault of the driver was measured (i.e. whether the driver considered that they caused the crash). Passengers and pedestrians were considered not at fault.

In NSW, CTP personal injury insurance is a privately underwritten, statutory, modified common law scheme. All motor vehicles travelling on public roads must be registered and insured for CTP. A CTP claim is made against the owner or driver of the vehicle at fault. Since April 2010, regardless of who was at fault, anyone injured in a motor vehicle crash can access limited entitlements (medical expenses and lost wages up to AU\$5,000). The WC scheme is publically underwritten with statutory benefits and administered by private insurers. To make a claim for injury the motor vehicle crash must have occurred during travel between place of employment, home and/or any work-related place and a person injured (regardless of fault). Further, the insurer must be notified of an injury within 48 hours and there is a legal obligation under the NSW WC legislation for employers to accommodate RTW of an injured employee, although there is no obligation under the NSW CTP legislation $[28,29]$. In 2015, the government regulators of these schemes merged to form the State Insurance Regulatory Authority (SIRA).

For both schemes, a claim must be lodged within six months of injury and the insurer has three months to determine final liability (accept or deny the claim). Provisional acceptance of liability enables earlier 
payment for medical expenses, and for WC weekly wage benefits based on work capacity and weeks since injury [29]. In CTP, lump sum payments are available on a case-by-case basis for financial hardship. Entitlements include past and future losses across each scheme (e.g. medical expenses, loss of income, and pain and suffering/impairment) [28, 29]. Legal representation can also be obtained at any time for either scheme.

\section{Outcome measure - return to work}

There are no standardised measures for RTW. Those used in this study encapsulated self-reported duration and level of work $[6,7]$. The primary measure was time (days) to return to work (i.e. from date of injury to date of RTW). At each time period work status $(\mathrm{Y} / \mathrm{N})$ was measured. Working participants were then asked the date of RTW, if they were working full/modified duties (e.g. lifting restrictions), and full-time (usually working at least 35 hours per week) or part-time (usually working 1-35 hours per week) [30]. These questions were asked pre-injury (baseline) and post-injury (six, 12 and 24 months). Participants were also asked if their inability to RTW was crash-related, and if they had changed their occupation following injury.

\section{Data analysis}

RTW baseline characteristics, including full/modified duties and full/part-time, were summarised using descriptive statistics. Outcomes were assessed using survival analysis with Cox proportional hazards regression models employed to determine the multivariate predictors of time to RTW. The Cox model is considered an appropriate approach to accounting for time to an event [31]. The variables selected for the model have been shown to be independent predictors of RTW and/or potential confounders of poorer outcomes in other research [7, 16-18]. Similarly, compensation-related factors were selected for the same reasons $[2,4,7,8]$.

Selection of variables for the Cox model was based on associations between baseline characteristics, including compensation related factors and time to RTW. These were assessed using the logrank test to detect differences in the survival distributions across categorical variables. All variables with $p$-value $\leq 0.20$ were entered into the Cox regression model using a backward elimination process with an entry p-value $<0.05$ and an exit p-value $<0.10$. Variable selection was confirmed through explained variation and predictive accuracy using $\mathrm{R}$-squared values calculated with the Cox and Snell R-squared approach and a concordance index [32]. The concordance index is a widely applicable measure with progressive addition of factors that improve discrimination of the model. When a variable is added and the c-index plateaus or decreases, that variable and additional variables can be regarded as noise and excluded to avoid over fitting in the model [31]. Furthermore, explained variance using R-squared describes the relative importance of adding each variable into the Cox regression model.

Data from participants where the endpoint (RTW) had not occurred or was unknown at 24 months were considered censured. In studies of survival, in which the outcome is death, Hazard Rate Ratios (HRR) greater than 1 indicates risk. However, in this study, the fewer cumulative days of time taken to RTW, the more positive the outcome, in terms of injury recovery/RTW, and the higher the HRR. Therefore, a HRR less than 1 indicates higher risk and a longer time taken to RTW. A test of proportionality was performed on all predictors, and claim made and legal representation. The assumption of proportionality was not violated $(p>0.05)$ [33].

A separate Cox proportional hazards regression analysis was done for compensation related variables (claim made and legal representation), as these variables were measured at the six month time point and only a portion of participants made a claim and sought legal representation. In this Cox regression, claim made and legal representation were added to the final variables in the baseline RTW model. All data analysis was performed using SPSS statistical software version 22 (SPSS Inc, USA).

\section{Results}

From November 2007 to February 2011, 840 eligible participants were admitted to hospital across both sites, 491 were screened (349 eligible participants missed being screened due to resource limitations), and 452 (92\%) consented to participate. There were 31 refusals and eight who were discharged and unable to be contacted. Additional information about recruitment and follow up for study participants is shown in Fig. 1. There were significant differences $(p<0.05)$ in baseline characteristics, namely socio-demographic and socio-economic factors, between those working and not working pre-injury. These differences were expected and people not working were not included in the analyses (data not shown). Of the 452 participants, our subsequent results are based on the subset of 334 (74 \%) participants who worked up to the time of injury.

\section{Baseline characteristics}

Baseline characteristics were: mean age 36 years (13.9 Standard Deviation [SD]); 80 \% male; $72 \%$ self-assessed very good-excellent pre-injury health; $83 \%$ annual household income $>\mathrm{AU} \$ 40,000$. Follow up data was available for 233 (70\%), 210 (63\%), and $182(54 \%)$ participants at six, 12 and 24 months respectively. There were significant differences between responders and non-responders at six, 12 months and 24 months; this is 


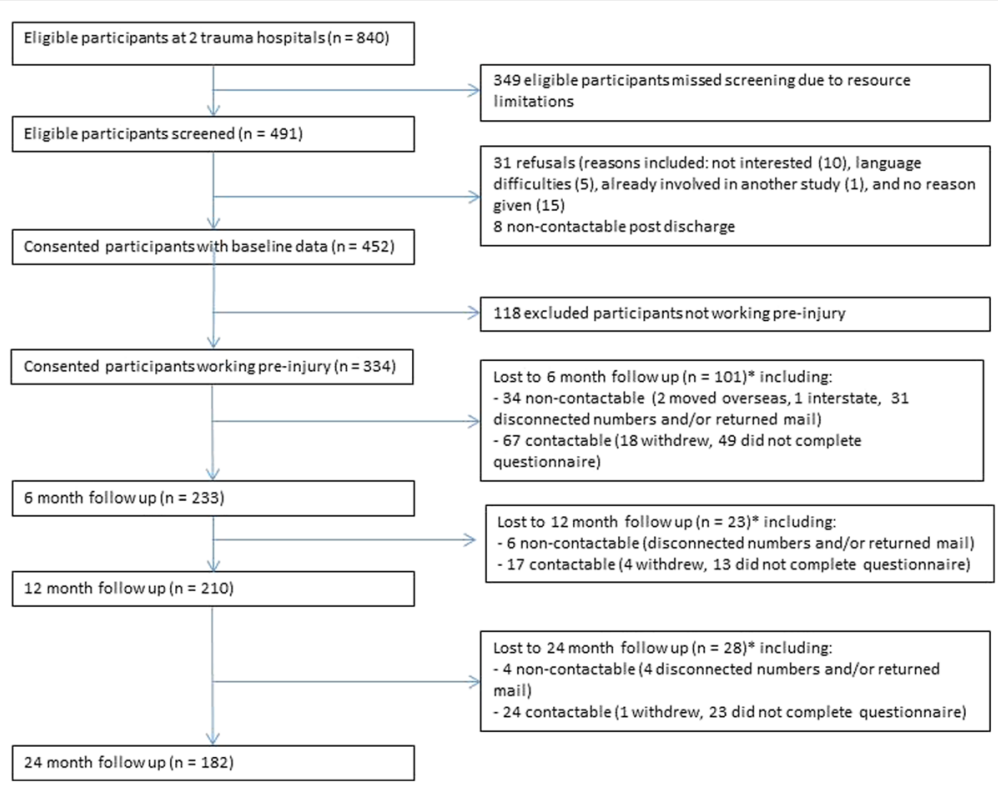

Fig. 1 Flow chart of study participants

explained in Table 1. For all other variables there was no significant difference $(\mathrm{p}>0.05)$ (data not shown). In addition, there were significant differences between those participants that made a claim at six months $(n=$ $140)$ and those that did not $(n=91)$. This reflected eligibility to claim under the NSW legislation: those participants more likely to make a claim were not at fault (78 \%), had crashed on a public road (94\%), and worked pre-injury $(77 \%)$. For all other variables there was no significant difference $(\mathrm{p}>0.05)$ (data not shown).

\section{Characteristics of return to work}

At baseline, of the 334 who worked, $83 \%$ were full-time and $96 \%$ performed full duties. At six months, of the 146 (63\% of responders) who worked, $65 \%$ were fulltime and $64 \%$ performed full duties. At 12 months, of the 149 (71\% of responders) who worked, $73 \%$ were full-time and $69 \%$ performed full duties. At 24 months, of the 137 (75\% of responders) who worked, $81 \%$ were full-time and $79 \%$ performed full duties. In addition, at six months, failure to RTW was related to the crash for $84 \%$, and $10 \%$ had changed occupation. At 12 months, failure to RTW was related to the crash for $80 \%$, and $16 \%$ had changed occupation. At 24 months, failure to RTW was related to the crash for $81 \%$, and $22 \%$ had changed occupation.

Overall, there were nine participants who initially returned to work at either six or 12 months but did not remain at work during the subsequent follow up pe$\operatorname{riod}(\mathrm{s})$. Of these, five participants worked at six and 12 months but not at 24 months. Two participants returned to work at 12 months but no longer worked at
24 months, and two participants who had returned to work at six months no longer worked at 24 months.

\section{Predictors of time to return to work}

For all 334 study participants, the median time to RTW was 231 days (95\% CI 190.05-271.95). For RTW, the probability of participants working at six months was $40.6 \%$, at 12 months was $62.2 \%$, and at 24 months was $74.2 \%$. This is based on the Kaplan-Meier estimates of the survival curve as shown in Fig. 2. Associations between baseline characteristics and time to RTW are shown in Table 2. The significant variables identified in the logrank test, including age and sex, were entered into the Cox proportional hazards regression model. Based on the variables identified from the backwards elimination process, Table 3 shows the concordance (cindex) and R-squared of each of the variables as they were added to the Cox model. The c-index plateaued at the variable of smoking history; the remaining variables were not included in the model. Of the variables that were not significant only age and sex were deemed necessary to be included in the Cox model.

The Cox proportional hazards regression model for risks of time to RTW is presented in Table 4. The significant risks of taking a longer time to RTW were: greater injury severity (NISS), namely those with severecritical injuries as compared to those with minormoderate and serious injuries, and lower occupational skill levels as compared to managerial or professional skill levels. In the same model, the significant risks of taking a shorter time to RTW were: full-time pre-injury work hours compared to part-time pre-injury work 
Table 1 Baseline characteristics and health status of participants in the study compared to non-participants at six, 12 and 24 month follow up

\begin{tabular}{|c|c|c|c|c|c|c|c|c|c|}
\hline \multirow[b]{2}{*}{ Variable } & \multicolumn{3}{|c|}{ Participation at six months } & \multicolumn{3}{|c|}{ Participation at 12 months } & \multicolumn{3}{|c|}{ Participation at 24 months } \\
\hline & No $(n=101)$ & $\operatorname{Yes}^{a}(n=233)$ & $P$ & No $(n=124)$ & $\operatorname{Yes}^{\mathrm{a}}(n=210)$ & $P$ & No $(n=151)$ & $\mathrm{Yes}^{\mathrm{a}}(n=182)$ & $\mathrm{p}$ \\
\hline Age (years), Mean (SD) & $31.9(12.0)$ & $38.2(14.2)$ & $* *$ & $31.7(11.5)$ & $39.0(14.4)$ & $* *$ & $31.5(11.7)$ & $40.3(14.3)$ & ** \\
\hline New Injury Severity Score, No. (\%) & & & NS & & & * & & & NS \\
\hline Minor - moderate 1-8 & $22(21.8)$ & $41(17.6)$ & & $27(21.8)$ & $36(17.1)$ & & $33(21.9)$ & $30(16.5)$ & \\
\hline Serious 9-15 & $50(49.5)$ & $94(40.3)$ & & $61(49.2)$ & $83(39.5)$ & & $71(47.0)$ & $73(40.1)$ & \\
\hline Severe - critical 16-75 & $29(28.7)$ & $98(42.1)$ & & $36(29.0)$ & $91(43.3)$ & & $47(31.1)$ & 79 (43.4) & \\
\hline Marital status, No. (\%) & & & ** & & & $* *$ & & & $* *$ \\
\hline Single & $60(60.0)$ & $87(37.5)$ & & $68(54.8)$ & $79(38.0)$ & & $86(57.0)$ & $61(33.9)$ & \\
\hline Married/defacto & $36(36.0)$ & $131(56.5)$ & & $53(42.7)$ & $114(54.8)$ & & $61(40.4)$ & $105(58.3)$ & \\
\hline Divorced/widowed & $4(4.0)$ & $14(6.0)$ & & $3(2.4)$ & $15(7.2)$ & & $4(2.6)$ & $14(7.8)$ & \\
\hline Occupation skill level ${ }^{b}$, No. (\%) & & & * & & & NS & & & * \\
\hline Managers/professionals & $20(19.8)$ & $58(25.0)$ & & $23(18.5)$ & $55(26.3)$ & & $60(26.1)$ & $38(17.1)$ & \\
\hline Tradespersons & $26(25.7)$ & $85(36.6)$ & & $36(29.0)$ & 75 (35.9) & & $71(30.9)$ & $55(24.8)$ & \\
\hline Intermediate clerical & $17(16.8)$ & $35(15.1)$ & & $21(16.9)$ & $31(14.8)$ & & $27(11.7)$ & $37(16.7)$ & \\
\hline Elementary related & $38(37.6)$ & $54(23.3)$ & & $44(35.5)$ & $48(23.0)$ & & $53(23.0)$ & $72(32.4)$ & \\
\hline Body Mass Index $(\mathrm{BMI})^{\mathrm{C}}\left(\mathrm{kg} / \mathrm{m}^{2}\right)$ & & & * & & & NS & & & NS \\
\hline <18.50 (underweight) & $4(4.0)$ & $2(0.9)$ & & $4(3.2)$ & $2(1.0)$ & & $4(2.6)$ & $2(1.1)$ & \\
\hline 18.50-24.99 (normal) & $45(44.6)$ & 78 (33.8) & & $50(40.3)$ & $73(35.1)$ & & $64(42.4)$ & $58(32.2)$ & \\
\hline 225.00 (overweight) & $35(34.7)$ & $89(38.5)$ & & $47(37.9)$ & $77(37.0)$ & & $53(35.1)$ & $71(39.4)$ & \\
\hline$\geq 30.00$ (obese) & $17(16.8)$ & $62(26.8)$ & & $23(18.5)$ & $56(26.9)$ & & $30(19.9)$ & $49(27.2)$ & \\
\hline Smoking history, No. (\%) & & & * & & & NS & & & NS \\
\hline Current smoker & $38(38.0)$ & $51(22.0)$ & & $40(32.5)$ & $49(23.4)$ & & $48(32.0)$ & $40(22.1)$ & \\
\hline Ex-smoker & $23(23.0)$ & $67(28.9)$ & & $32(26.0)$ & $58(27.8)$ & & $36(24.0)$ & $54(29.8)$ & \\
\hline Never smoked & $39(39.0)$ & $114(49.1)$ & & $51(41.5)$ & $102(48.8)$ & & $66(44.0)$ & $87(48.1)$ & \\
\hline $\begin{array}{l}\text { Self-reported chronic } \\
\text { illnesses (yes) No. (\%) }\end{array}$ & $17(16.8)$ & $76(32.6)$ & $* *$ & $26(21.0)$ & $67(31.9)$ & * & $35(23.2)$ & $58(31.9)$ & NS \\
\hline Medication use (current), No. (\%) & $11(10.9)$ & $56(24.1)$ & ** & $13(10.5)$ & $54(25.8)$ & ** & $19(12.6)$ & $48(26.5)$ & $* *$ \\
\hline Vehicle type, No. (\%) & & & * & & & * & & & * \\
\hline Motor vehicle & $61(60.4)$ & $114(48.9)$ & & $71(57.3)$ & $104(49.5)$ & & $87(57.6)$ & $88(48.4)$ & \\
\hline Motorcycle & $31(30.7)$ & $109(46.8)$ & & $42(33.9)$ & $98(46.7)$ & & $53(35.1)$ & $87(47.8)$ & \\
\hline Bicycle & $9(8.9)$ & $10(4.3)$ & & $11(8.9)$ & $8(3.8)$ & & $11(7.3)$ & $7(3.8)$ & \\
\hline
\end{tabular}

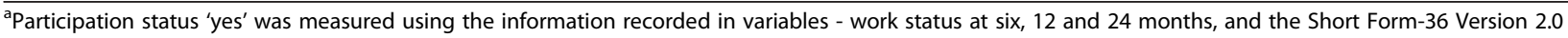
(SF36v2), Physical Component Score (PCS) at six, 12 and 24 months respectively

** $P<0.01,{ }^{*} P<0.05$, NS not significant

${ }^{\text {b} T h e ~ m e a s u r e ~ f o r ~ o c c u p a t i o n ~ i s ~ f r o m ~ t h e ~ A u s t r a l i a n ~ S t a n d a r d ~ C l a s s i f i c a t i o n ~ o f ~ O c c u p a t i o n s ~(A S C O), ~ C a t . ~ N o . ~ 1220.0, ~ A u s t r a l i a n ~ B u r e a u ~ o f ~ S t a t i s t i c s ~ 1997 . ~ S e e ~}$ Table 2, Occupational skill level for all categories

'BMI classification is from the Global Database on Body Mass Index, World Health Organisation

hours; recovery expectations for usual activities of $\leq 90$ days compared to recovery expectations for usual activities of $\geq 90$ days, and having very good self-assessed preinjury health status as compared to having excellent self-assessed health status.

In terms of compensation related factors, overall $140 / 231$ (60 \%) made a claim at six months (there was missing data for $2 / 233$ responders for the compensation related questions at six months). Of those who made a claim, 95/140 (68 \%) sought legal representation at six months. Making a claim at six months was not associated with time to RTW, the HRR was 0.89 (95\% CI $0.60-1.33)$. The logrank analysis of seeking legal representation at six months was associated with a longer time to RTW (see Table 2). However, in the Cox regression with baseline variables included, legal representation was not associated with time to RTW; the HRR was 0.81 (95 \% CI 0.54-1.21). 


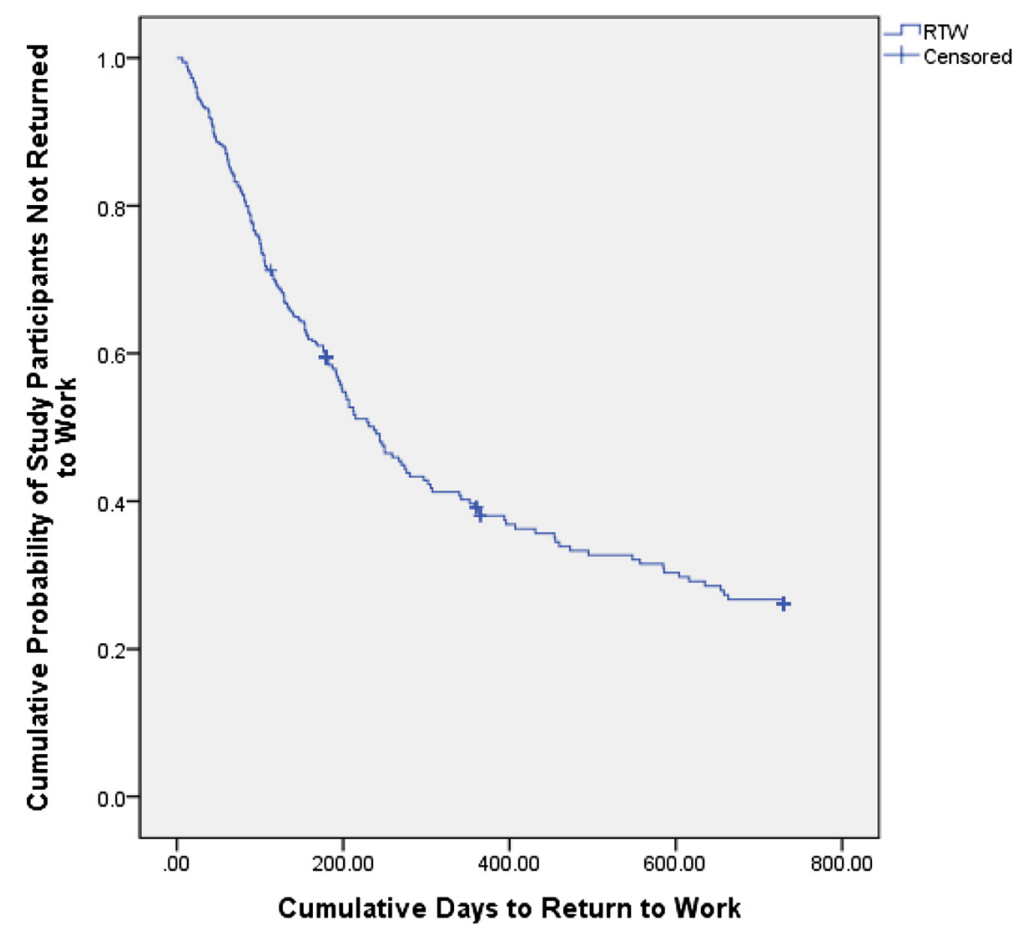

Fig. 2 Kaplan-Meier estimate of the cumulative time (days) to return to work for study participants $(n=334)$

\section{Discussion}

Time to RTW was associated with both injury and noninjury related factors in a cohort with motor vehicle related moderate-severe orthopaedic injuries. The main findings were that greater injury severity and lower occupational skill levels were significant risks of a longer time to RTW. Whereas, recovery expectations for usual activities of $\leq 90$ days, full-time pre-injury work hours, and very good self-assessed pre-injury health status were significant risks of a shorter time to RTW. Legal representation at six months was not associated with time to RTW.

\section{Predictors of time to return to work}

In our study, the significance of injury severity as a risk of time to RTW was driven by those with severe-critical injuries (ISS 16-75). Similarly, the significance of occupation was driven by those with lower occupational skill levels such as elementary workers and tradespersons. Existing research confers that injury severity and occupational skill level are predictors of RTW, particularly for lower limb injuries [3, 4, 8, 34, 35]. This result is not unforeseen given the socio-demographic profile of the cohort - mean age 36 years, $80 \%$ male, and $33 \%$ tradespersons, advanced clerical or service workers. Adequate physical function is likely to be an important component of work. In other research, these factors have been independent predictors of RTW, although the level of evidence is variable [7]. Likewise, the significance of full-time pre- injury work hours and very good pre-injury health status is likely to be dependent on the study population. These factors have been reported as predictors of a shorter time to RTW and recovery $[4,7,16,36]$. Again, results are inconsistent and measures vary. For example, higher baseline income or job involvement is measured instead of pre-injury work hours $[4,7]$.

Recovery expectations and illness perception, and low self-efficacy, are significant predictors of RTW rates and/or recovery across a range of injuries and illnesses $[7,24,25,37,38]$. This shows they are robust predictors of RTW that relate to the individual rather than a specific diagnosis. These predictors are complex and multidimensional [24, 37, 39]. Theoretically, self-efficacy (i.e. person's belief in their own competence) materialises during childhood and evolves throughout life. Those with strong self-efficacy master problems, recovering expeditiously; those with weak self-efficacy avoid challenges, focusing on negative outcomes [40]. Similarly, illness perception is based on a self-regulatory model that appraises a person's response to their illness event [41]. In other words, how well you think you will recover can influence how well you actually recover.

The association between making a claim and legal representation, and poor RTW rates or recovery is well documented $[7,10]$. As before, results vary according to the study population, outcome measures, and possibly the compensation scheme. In this study, the logrank test between legal representation and time to RTW was 
Table 2 Baseline characteristics and time to RTW of study participants $(n=334)$

\begin{tabular}{llll}
\hline Variable & No. & Median & Logrank \\
& $(\%)$ & time to & $\begin{array}{l}\text { Test } \\
\text { RTW }\end{array}$ \\
& R value \\
\hline
\end{tabular}

Age

334

Injury Severity Score

0.09

Minor - moderate 1-8

$84 \quad 204$

Serious 9-15

$198 \quad 240$

Severe - critical 16-75

$52 \quad 259$

New Injury Severity Score

Minor - moderate 1-8

$63 \quad 204$

Serious 9-15

$144 \quad 203$

Severe - critical 16-75

$127 \quad 305$

Index of Relative Socioeconomic

Disadvantage ${ }^{a}$

$\begin{array}{lll}\text { Most disadvantaged } & 89 & 215 \\ \text { Disadvantaged } & 34 & 365 \\ \text { Average } & 64 & 270 \\ \text { Advantaged } & 78 & 207 \\ \text { Most advantaged } & 69 & 198 \\ \text { Sex } & & \\ \text { Female } & 67 & 199 \\ \text { Male } & 267 & 244\end{array}$

Marital status

Single

Married/de facto

Divorced/widowed/separated

Education skill level ${ }^{b}$

Bachelor degree and above

Certificate and advanced diploma

Secondary education

Pre-primary and primary education

Occupation skill level ${ }^{b}$

Managers/administrators/professionals/ associate professionals

Tradespersons/advanced clerical and $\quad 111 \quad 229$ service workers

Intermediate clerical/sale/service $\quad 52 \quad 396$

production/transport workers

Elementary clerical/sales/service/ $\quad 92 \quad 340$ labourers/related workers

Work level before injury

Full Duties

$321 \quad 231$

Part Duties

$13 \quad 213$

Work hours before injury ${ }^{c}$

Full-time

Part-time

Pre-injury job satisfaction ${ }^{d}$

Satisfied

Not Satisfied

0.002

0.57

0.13

0.01
Table 2 Baseline characteristics and time to RTW of study participants ( $n=334)$ (Continued)

Recovery expectations for work

Yes

0.08

No

$<0.001$

Recovery expectations for usual activities

$298 \quad 212$

$32 \quad 280$

$\leq 90$

$202 \quad 177$

$>90$

111455

Language other than English

Yes

$108 \quad 250$

$226 \quad 231$

Total yearly household income ${ }^{e}$ (before tax, $\mathrm{AU}$ ) excluding number of people in household

$\begin{array}{lll}\leq \$ 39,999 & 53 & 302 \\ \$ 40,000-\$ 79,999 & 110 & 250 \\ \geq \$ 80,000 & 148 & 194\end{array}$

Total adjusted yearly household income $e^{e}$ (before tax, AU) including number of people in household

$\begin{array}{lll}\leq \$ 39,999 & 153 & 240 \\ \$ 40,000-\$ 79,999 & 121 & 250 \\ \geq \$ 80,000 & 37 & 154\end{array}$

Body Mass Index (BMI) ${ }^{\mathrm{f}}\left(\mathrm{kg} / \mathrm{m}^{2}\right)$

$$
<18.50 \text { (underweight) }
$$

$6 \quad 407$

18.50-24.99 (normal) $123 \quad 213$

$\geq 25.00$ (overweight) $\quad 124 \quad 203$

$\geq 30.00$ (obese)

79302

Smoking history

Current smoker

Ex-smoker

$89 \quad 394$

$90 \quad 207$

153199

Self-reported chronic illnesses

$$
\text { Yes }
$$

No

$93 \quad 215$

$241 \quad 240$

Medication use

Yes

$67 \quad 229$

No

$266 \quad 237$

Recent injury other than crash

Yes

No

$16 \quad 365$

$316 \quad 231$

Risk of long term harm due to alcohol consumption ${ }^{\mathrm{g}}$ (standard drinks ${ }^{\mathrm{h}} /$ week)

Low risk - $\leq 28$ male or $\leq 14$ female

$311 \quad 231$

Risky - 29-42 male or 15-28 female

$13 \quad 358$

High risk - $\geq 43$ male or $\geq 29$ female

$9 \quad 244$

Risk of short term harm due to alcohol consumption ${ }^{9}$ (yes)
Yes
$116 \quad 297$
No
$218 \quad 215$ 
Table 2 Baseline characteristics and time to RTW of study participants $(n=334)$ (Continued)

\begin{tabular}{|c|c|c|c|}
\hline Self-reported at-fault & & & 0.04 \\
\hline Yes & 125 & 203 & \\
\hline No & 208 & 250 & \\
\hline Vehicle type & & & 0.02 \\
\hline Motor vehicle & 175 & 276 & \\
\hline Motorcycle & 140 & 199 & \\
\hline Bicycle & 19 & 182 & \\
\hline Pre-morbid neck pain in last 6 months & & & 0.70 \\
\hline Yes & 15 & 203 & \\
\hline No & 319 & 237 & \\
\hline Post-morbid neck pain & & & 0.74 \\
\hline Yes & 59 & 215 & \\
\hline No & 275 & 231 & \\
\hline Crash on a public road & & & 0.06 \\
\hline Yes & 297 & 240 & \\
\hline No & 37 & 156 & \\
\hline Self-assessed pre-injury health status ${ }^{i j}$, & & & 0.03 \\
\hline Excellent & 103 & 240 & \\
\hline Very good & 137 & 199 & \\
\hline Good & 78 & 250 & \\
\hline Fair-Poor & 16 & - & \\
\hline Claim made by 6 months & & & 0.08 \\
\hline Yes & 140 & 178 & \\
\hline No & 91 & 120 & \\
\hline Legal representation at 6 months & & & 0.007 \\
\hline Yes & 95 & 199 & \\
\hline No & 136 & 122 & \\
\hline
\end{tabular}

The Index of Relative Socioeconomic Disadvantage (IRSD) is a summary measure of economic and social conditions within a particular area/postcode (e.g. employment, fluency in English and household size). It is taken from the Census of Population and Housing: Socio-Economic Indexes for Areas (SEIFA), Cat no. 2039.0.55.001: Australian Bureau of Statistics; 2001. A low score is indicative of greater socioeconomic disadvantage

${ }^{\mathrm{b}}$ Measures for occupation and education are from the Australian Standard Classification of Occupations (ASCO), Cat. No. 1220.0, Australian Bureau of Statistics 1997 and the Australian Standard Classification of Education (ASCED), Cat. No. 1272.0, Australian Bureau of Statistics 2001

'Measures for full-time (usually working at least 35 hours per week) and part-time (usually working 1-35 hours per week) are from the Australian Health Survey: Users' Guide, 2011-13, Cat. No. 4363.0.55.001, Australian Bureau of Statistics dPre-injury job satisfaction is based on the stem question from the Measure of Job Satisfaction questionnaire by Traynor, M. and Wade, B. 1993

${ }^{\text {e}}$ Categories of income are from the Household, Income and Labour Dynamics in Australia (HILDA) Survey Wave 6 Household Questionnaire

${ }^{\mathrm{f}} \mathrm{BMI}$ classification is from the Global Database on Body Mass Index, World Health Organisation

${ }^{9}$ Questions to determine risk of harm were from the Alcohol Use Disorders Identification Test: Self-Report Version (AUDIT-C) were resourced from the Drink-less program, The University of Sydney. http://sydney.edu.au/medicine/ addiction/drinkless/resources.php

${ }^{\mathrm{h}} 1$ standard drink contains 12.5 millilitres or 10 grams of alcohol according to the National Health and Medical Research Council (NHMRC), Australian Alcohol Guidelines Health Risks and Benefits, October 2001

'Self-assessed health status is based on Question 1 from the Short Form-36, Version 2.0, (SF36v2)

${ }^{j}$ No median score for fair-poor self-assessed pre-injury health status, the median indicates that more than half did not return to work (mean $=529$ days)
Table 3 Concordance (c-index), R squared as each variable is added into the model

\begin{tabular}{|c|c|c|}
\hline Factor & R-squared & C-index \\
\hline Recovery expectations for usual activities & 0.087 & 0.605 \\
\hline Occupation skill level ${ }^{a}$ & 0.104 & 0.643 \\
\hline New injury severity score & 0.121 & 0.656 \\
\hline Self-assessed pre-injury health status ${ }^{\mathrm{b}}$ & 0.154 & 0.662 \\
\hline Work hours before injury ${ }^{c}$ & 0.177 & 0.671 \\
\hline Smoking history & 0.194 & 0.678 \\
\hline Education skill level $^{a}$ & 0.197 & 0.679 \\
\hline Recovery expectations for work & 0.206 & 0.687 \\
\hline Injury severity score & 0.212 & 0.687 \\
\hline Total yearly household income $^{d}$ & 0.225 & 0.695 \\
\hline Self-reported at fault & 0.227 & 0.695 \\
\hline Language other than English & 0.240 & 0.699 \\
\hline Crash on public road & 0.241 & 0.700 \\
\hline $\begin{array}{l}\text { Risk of short term harm due to alcohol } \\
\text { consumptione }\end{array}$ & 0.244 & 0.700 \\
\hline Age & 0.251 & 0.704 \\
\hline Sex & 0.252 & 0.707 \\
\hline
\end{tabular}

The blank row indicates the point where the concordance index plateaus Factors above this were maintained while factors below this were dropped ${ }^{a}$ Measures for occupation and education are from the Australian Standard Classification of Occupations (ASCO), Cat. No. 1220.0, Australian Bureau of Statistics 1997 and the Australian Standard Classification of Education (ASCED), Cat. No. 1272.0, Australian Bureau of Statistics 2001

${ }^{\text {b}}$ Self-assessed health status is based on Question 1 from the Short Form 36, version 2, (SF36v2)

cMeasures for full-time (usually working at least 35 hours per week) and part-time (usually working 1-35 hours per week) are from the Australian Health Survey: Users' Guide, 2011-13, Cat. No. 4363.0.55.001, Australian Bureau of Statistics

${ }^{d}$ Categories of income are from the Household, Income and Labour Dynamics in Australia (HILDA) Survey Wave 6 Household Questionnaire.

${ }^{e}$ Questions to determine risk of harm were from the Alcohol Use Disorders Identification Test: Self-Report Version (AUDIT-C) were resourced from the Drink-less program, The University of

Sydney. http://sydney.edu.au/medicine/addiction/drinkless/resources.php

significant. However, baseline variables in the Cox regression could be a common cause of legal representation and time to RTW. In addition, it may be that people seek legal representation because they haven't returned to work and/or because of other intervening factors, or those who seek legal representation are more likely to take longer to RTW. It is not possible to address these issues in this study. Regardless, there was no association once baseline variables were taken into account.

More recently, within a compensable setting, legal representation has been linked to socio-economic and psychosocial factors such as: stressfulness of making a claim; poorer baseline mental health; higher disability; socio-economic disadvantage; and financial entitlements [42-44]. This suggests that people seeking legal representation have different characteristics compared to 
Table 4 Cox proportional hazards regression model for predictors of time (days) to RTW

\begin{tabular}{|c|c|c|c|c|c|}
\hline Factor & B & SE & $P$ value & $\mathrm{HRR}$ & $95 \% \mathrm{Cl}$ \\
\hline Age & 0.009 & 0.006 & 0.10 & 1.010 & $0.998-1.021$ \\
\hline Sex (Male) & -0.038 & 0.202 & 0.851 & 0.963 & $0.648-1.430$ \\
\hline New Injury Severity Score & & & 0.007 & & \\
\hline Minor - moderate 1-8 & - & - & - & - & - \\
\hline Serious 9-15 & -0.170 & 0.202 & 0.401 & 0.844 & $0.568-1.254$ \\
\hline Severe - critical 16-75 & -0.619 & 0.216 & 0.004 & 0.539 & $0.353-0.822$ \\
\hline Occupation skill level $^{a}$ & & & 0.05 & & \\
\hline Managers/administrators/professionals/associate professionals & - & - & - & - & - \\
\hline Tradespersons/advanced clerical and service workers & -0.355 & 0.204 & 0.081 & 0.701 & $0.470-1.045$ \\
\hline Intermediate clerical/sale/service production/transport workers & -0.311 & 0.249 & 0.211 & 0.733 & $0.450-1.193$ \\
\hline Elementary clerical/sales/service/labourers/related workers & -0.632 & 0.227 & 0.003 & 0.532 & $0.341-0.829$ \\
\hline Work hours before injury (Full-time) ${ }^{b}$ & 0.688 & 0.232 & 0.003 & 1.989 & $1.261-3.136$ \\
\hline Recovery expectations for usual activities ( $\leq 90$ days) & 0.741 & 0.174 & $<0.001$ & 2.099 & $1.494-2.949$ \\
\hline Self-assessed pre-injury health status ${ }^{c}$ & & & 0.005 & & \\
\hline Excellent & - & - & - & - & - \\
\hline Very good & 0.343 & 0.184 & 0.062 & 1.409 & $0.983-2.019$ \\
\hline Good & -0.111 & 0.219 & 0.612 & 0.895 & $0.582-1.376$ \\
\hline \multirow[t]{2}{*}{ Fair-Poor } & -1.029 & 0.476 & 0.031 & 0.357 & $0.141-0.908$ \\
\hline & & & 0.090 & & \\
\hline Current smoker & - & - & - & - & - \\
\hline Ex-smoker & 0.368 & 0.222 & 0.097 & 1.445 & $0.936-2.232$ \\
\hline Never smoked & 0.434 & 0.201 & 0.031 & 1.543 & $1.041-2.288$ \\
\hline
\end{tabular}

a Measures for occupation and education are from the Australian Standard Classification of Occupations (ASCO), Cat. No. 1220.0, Australian Bureau of Statistics 1997 ${ }^{\mathrm{b}}$ Measures for full-time (usually working at least 35 hours per week) and part-time (usually working 1-35 hours per week) are from the Australian Health Survey: Users' Guide, 2011-13, Cat. No. 4363.0.55.001, Australian Bureau of Statistics

'Self-assessed health status is based on Question 1 from the Short Form-36, Version 2.0, (SF36v2)

other compensable and non-compensable participants; which could be partly or wholly responsible for prolonging their RTW.

Other research shows that people seek legal advice to help with the adversarial claims processes, communication and administrative deficits with insurers, perceived illegitimacy of their injury, and accessing reasonable entitlements [11-13]. It may not be 'legal representation' per se that is associated with RTW but these other factors. In addition, there is a lack of granularity when classifying exposure to legal representation. For example, the 'no win, no fee' legal services in NSW CTP and WC schemes provide a financial incentive for plaintiff lawyers to take viable cases where extracting a reasonable fee is more likely (e.g. people with more serious injuries, pre-existing and/or crash related factors that could allow access to greater financial entitlements) [45].

\section{Characteristics of return to work}

Measuring RTW is challenging - definitions and durations are diffuse [7]. In our study RTW was measured at three time periods inclusive of time (days) to RTW, full/part-time hours and full/modified duties. At each period the majority were working full-time on full duties but below baseline figures. In similar studies RTW varied from $28-68 \%$ at 6 months [3, 4]; $42 \%$ at 12 months [4]; and $51 \%$ at 24 months [4]. It is difficult to compare RTW rates due to heterogeneity between populations and the multidimensional nature of facilitators and barriers for RTW [9].

Taking into account the unemployment rate in Australia over the follow up period $(4.2 \%$ in 2008 $5.4 \%$ in 2013) [46, 47] and the socio-demographic profile of the study population, the limited RTW rate is of concern. Accepting that work is good for health and well-being, the converse is also true and poor health contributes to lost productivity and lower socio-economic status [1].

\section{Strengths and limitations}

This prospective study was a representative cohort of moderate-severe injuries following motor vehicle related orthopaedic trauma. Standardised and validated measures were used with repeated follow up. 
Additional measures at baseline would have been beneficial including initial pain intensity, baseline mental health, and other psychological measures. These have been associated with poorer outcomes following trauma $[3,4,16,17]$. Further, there appears to be a relationship between these factors and having a compensation claim $[42,44]$. The inclusion of medical and/or vocational interventions, individual job characteristics/tasks, and workplace/organisational factors would have been useful. These determinants of RTW are often population specific and amenable to intervention in a compensation setting $[6,9]$.

Another limitation was moderate loss to follow up. The study population characteristics were a plausible reason for loss to follow up. Participants were predominantly younger males of lower socioeconomic status who were in semi-unskilled occupations. They were often contactable (see Fig. 1) but would not return the questionnaires. Those lost to follow up were younger, less likely to be married, and less likely to be currently taking medication. If they had remained in the study, these differences could have influenced time to RTW. Lastly, these findings require validation in future research with larger cohorts and different study populations.

\section{Future research and policy implications}

Predictors of RTW are multidimensional and cover numerous individual, work, organisational and societal domains, which makes high quality research challenging. Despite the abundant research to date, much remains inconclusive [7]. It is important to focus on factors amenable to intervention. Injury severity, pre-injury work hours and health status are relatively static outside the bounds of injury prevention programs.

However, expectations for return to usual activities, illness perception and self-efficacy are more dynamic. Validated measures are now available to gauge this risk factor of poor RTW and/or recovery [37, 39, 48]. Investing in interventions such as education, coaching or multidisciplinary programs could improve RTW rates by adjusting expectations; thereby reducing the associated costs of lost productivity [49-51].

There is a need to understand the paradigm of legal representation, and whether it is a valid measure. Measurement error can occur when the timing of exposure to a factor does not occur at baseline and/or there is questionable quality of the measure [52]. Since legal representation was measured at six months, not baseline, these results need to be interpreted cautiously. Further scheme specific, qualitative and quantitative research - principally of populations at risk for poor RTW - may assist to tease apart these complexities and provide researchers with ideas for RTW initiatives and scheme policy makers with opportunities for legislative or policy change if appropriate.
Lastly, taking into account the significance of lower occupational skill levels, it is crucial to improve RTW rates, and this is feasible, considering the strong evidence base for vocational rehabilitation. The coordination of early work-focused health interventions and accommodating workplaces with modified duties and hours is essential [53]. In WC jurisdictions this is not unforeseen, but in the CTP arena it remains arduous. There is often no legal impetus on the employer to reemploy an injured worker. In this instance, it may be necessary to advocate for legislative change or other policy initiatives like early identification and referral to vocational rehabilitation, or proactive claims management involving the employer to provide appropriate duties in the early post-injury period [53].

\section{Conclusions}

A longer time to RTW was associated with greater injury severity and lower occupational skill levels. A shorter time to RTW was associated with recovery expectations for usual activities of $\leq 90$ days, full-time pre-injury work hours, and very good self-assessed pre-injury health status following motor vehicle related orthopaedic trauma. Our findings reinforce existing research. There is an opportunity to trial interventions that address potentially modifiable factors such as poor recovery expectations. The issues surrounding legal representation are complex and require further research.

\section{Ethics approval and consent to participate}

The study was approved by the governing human research ethics committees (South Western Sydney Local Health District, South Eastern Sydney Local Health District, and The University of Sydney).

\section{Consent for publication}

Not applicable.

\section{Availability of data and materials}

Results from the dataset are presented in the paper. The full dataset is available from the first author upon request.

\footnotetext{
Abbreviations

ABS: Australian Bureau of Statistics; AIS: abbreviated injury scale; ASCED: australian standard classification of education; ASCO: Australian standard classification of occupations; AU: Australian dollar; AUDIT-C: alcohol use disorders identification test: self-report version; BEACH: bettering the evaluation of care and health; BMI: body mass index; CALD: culturally and linguistically diverse; Cl: confidence interval; CTP: compulsory third party; HILDA: household, income and labour dynamics in australia; HRR: hazards rate ratio; IRSD: index of relative socioeconomic disadvantage; ISS: injury severity score; NHMRC: National Health and Medical Research Council; NISS: new injury severity score; NSW: New South Wales; PCS: physical component score; RTW: return to work; SD: standard deviation; SEIFA: socio-economic indexes for areas; SF36V2: short form-36 version 2.0; WC: workers compensation.
} 


\section{Competing interests}

The authors declare that they have no competing interests.

\section{Authors' contributions}

Authors DM, IH and IC contributed significantly to: study conception and design; data acquisition, analysis and interpretation. Author YT conducted the statistical analysis and provided data interpretation. All authors contributed to drafting and critical revision of the manuscript. All authors read and approved the final manuscript.

\section{Authors' information}

Not applicable.

\section{Acknowledgements}

We would like to thank Dr Sam Adie, Dr Rajat Mittal and Ms Shirley Cross for their assistance with recruitment and data collection.

\section{Funding}

No funding was received for this study. Professor lan Cameron's salary is supported by an Australian National Health and Medical Research Council Practitioner Fellowship.

\section{Author details}

John Walsh Centre for Rehabilitation Research, The University of Sydney, Kolling Institute, Sydney, NSW, Australia. ${ }^{2}$ South Western Sydney Clinical School, UNSW Australia, Liverpool, Sydney, Australia. ${ }^{3}$ Ingham Institute for Applied Medical Research, Sydney, Australia. ${ }^{4}$ South Western Sydney Local Health District, Liverpool, Sydney, Australia.

\section{Received: 14 December 2015 Accepted: 7 April 2016}

\section{Published online: 19 April 2016}

\section{References}

1. Waddell G, Burton A. Is work good for your health and well-being? Norwich 2006. Available from: https://www.gov.uk/government/uploads/system/ uploads/attachment_data/file/214326/hwwb-is-work-good-for-you.pdf. Accessed May 2015

2. Gabbe B, Cameron P, Williamson O, Edwards E, Graves S, Richardson M. The relationship between compensable status and long-term patient outcomes following orthopaedic trauma. Med J Aust. 2007;187(1):14-7.

3. Clay FJ, Newstead SV, Watson WL, McClure RJ. Determinants of return to work following non life threatening acute orthopaedic trauma: a prospective cohort study. J Rehabil Med. 2010;42(2):162-9.

4. MacKenzie EJ, Bosse MJ, Kellam JF, Pollak AN, Webb LX, Swiontkowski MF, et al. Early predictors of long-term work disability after major limb trauma. J Trauma. 2006;61(3):688-94.

5. Murray CJ, Vos T, Lozano R, Naghavi M, Flaxman AD, Michaud C, et al. Disability-adjusted life years (DALYs) for 291 diseases and injuries in 21 regions, 1990-2010: a systematic analysis for the Global Burden of Disease Study 2010. [Erratum appears in Lancet. 2013 Feb 23;381(9867):628 Note: AlMazroa, Mohammad A [added]; Memish, Ziad A [added]]. Lancet. 2012; 380(9859):2197-223.

6. Krause N, Frank JW, Dasinger LK, Sullivan TJ, Sinclair SJ. Determinants of duration of disability and return-to-work after work-related injury and illness: challenges for future research. Am J Ind Med. 2001;40(4):464-84.

7. Clay FJ, Newstead SV, McClure RJ. A systematic review of early prognostic factors for return to work following acute orthopaedic trauma. Injury. 2010:41(8):787-803.

8. Hou W-H, Tsauo J-Y, Lin C-H, Liang H-W, Du C-L. Worker's compensation and return-to-work following orthopaedic injury to extremities. J Rehabil Med. 2008;40(6):440-5.

9. Foreman P, Murphy G, Swerissen H. Barriers and facilitators to return to work: A literature review. Melbourne: Australian Institute for Primary Care, La Trobe University; 2006. Available from: https://www.rtwsa.com/_data/ assets/pdf file/0009/31599/Facilitators-and-barriers-to-return-to-work-aliterature-review.pdf. Accessed May 2015.

10. Murgatroyd D, Casey P, Cameron I, Harris I. The Effect of Financial Compensation on Health Outcomes following Musculoskeletal Injury: Systematic Review. PLoS One. 2015;10(2). http://dx.doi.org/10.1371/journal. pone.0117597
11. Murgatroyd DF, Cameron ID, Harris IA. Understanding the effect of compensation on recovery from severe motor vehicle crash injuries: a qualitative study. Inj Prev. 2011;17(4):222-7.

12. Gabbe BJ, Sleney JS, Gosling CM, Wilson K, Sutherland A, Hart M, et al. Financial and employment impacts of serious injury: A qualitative study. Injury. 2014:45(9):1445-51.

13. Kilgour E, Kosny A, McKenzie D, Collie A. Interactions Between Injured Workers and Insurers in Workers' Compensation Systems: A Systematic Review of Qualitative Research Literature. J Occup Rehabil. 2015;25(1):160-81.

14. Bagley S, White $H$, Golomb B. Logistic regression in the medical literature: Standards for use and reporting, with particular attention to one medical domain. J Clin Epidemiol. 2001;54:979-85.

15. Harris IA, Young JM, Dalaludin BB, Solomon MJ. The effect of compensation on general health in patients sustaining fractures in motor vehicle trauma. $J$ Orthop Trauma. 2008:22(4):216-20.

16. Mock C, Mackenzie E, Jurkovich G, Burgess A, Cushing B, deLateur B, et al. Determinants of disability after lower extremity fracture. J Trauma. 2000; 49(6):1002-11

17. Bosse MJ, MacKenzie EJ, Kellam JF, Burgess AR, Webb LX, Swiontkowski MF, et al. An analysis of outcomes of reconstruction or amputation of leg-threatening injuries. N Engl J Med. 2002;347(24):1924-31.

18. Mackenzie EJ, Bosse MJ, Pollak AN, Webb LX, Swiontkowski MF, Kellam JF, et al. Long-term persistence of disability following severe lower-limb trauma. Results of a seven-year follow-up. J Bone Joint Surg Am. 2005;87(8):1801-9.

19. Association for the Advancement of Automotive Medicine. The Abbreviated Injury Scale, 1990 Revision, Update 98. Barrington, Illinois: Association for the Advancement of Automotive Medicine, 1998.

20. Baker SP, O'Neill B, Haddon Jr W, Long WB. The injury severity score: a method for describing patients with multiple injuries and evaluating emergency care. J Trauma. 1974;14(3):187-96.

21. Stevenson M, Segui-Gomez M, Lescohier I, Di Scala C, McDonald-Smith G. An overview of the injury severity score and the new injury severity score. Inj Prev. $2001 ; 7(1): 10-3$

22. Australian Bureau of Statistics. National Health Survey: Users' Guide - Electronic Publication, Cat.no. 4363.0.55.001: Australian Bureau of Statistics; 2004-05. Available from: http://www.abs.gov.au/ausstats/abs@.nsf/ProductsbyReleaseDate/ E88508137A2912FECA25762E0017C550?OpenDocument. Accessed Jan 2015.

23. Australian Institute of Health and Welfare. National Health Priority Areas: Australian Institute of Health and Welfare; 2005. Available from: http://www. aihw.gov.au/national-health-priority-areas/. Accessed Aug 2006.

24. Cole DC, Mondloch MV, Hogg-Johnson S. Early Claimant Cohort Prognostic Modelling G. Listening to injured workers: how recovery expectations predict outcomes-a prospective study. Can Med Assoc J. 2002;166(6): 749-54.

25. Mondloch MV, Cole DC, Frank JW. Does how you do depend on how you think you'll do? A systematic review of the evidence for a relation between patients' recovery expectations and health outcomes. [erratum appears in CMAJ 2001 Nov 13;165(10):1303]. Can Med Assoc J. 2001; 165(2):174-9.

26. Babor TF, Higgins-Biddle JC, Saunders JB, Monteiro MG. The Alcohol Use Disorders Identification Test, Guidelines Use in Primary Care, Second Edition: Department of Mental Health and Substance Dependence, World Health Organization; 2001. Available from: http://whqlibdoc.who.int/hq/2001/ WHO_MSD_MSB_01.6a.pdf. Accessed Jan 2015.

27. National Health and Medical Research Council. Australian Alcohol Guidelines, Health Risks and Benefits: National Health and Medical Research Council, Commonwealth of Australia; 2001. Available from: http://www. nhmrc.gov.au/publications/synopses/ds7syn.htm. Accessed Jan 2015

28. Motor Accidents Authority of NSW, If you've been injured: Motor Accidents Authority of NSW. Available from: http://www.maa.nsw.gov.au/if-youvebeen-injured. Accessed Aug2015.

29. WorkCover, NSW, Workers compensation claims Sydney, NSW: WorkCover, NSW. Available from: http://www.workcover.nsw.gov.au/workers-compensation-claims. Accessed Oct 2014

30. Australian Bureau of Statistics. 4363.0.55.001 - Australian Health Survey: Users' Guide, 2011-13 Canberra: Australian Bureau of Statistics. Available from: http://www.abs.gov.au/ausstats/abs@.nsf/Lookup/292447A4B945 4E9FCA257B8D00229E9F?opendocument. Accessed Oct 2013

31. Mclntosh G, Frank J, Hogg-Johnson S, Bombardier C, Hall H. Prognostic factors for time receiving workers' compensation benefits in a cohort of patients with low back pain. Spine (Phila Pa 1976). 2000;25(2):147-57. 
32. Cox DR, Snell EJ. Analysis of Binary Data. 2nd ed. London: Chapman \& Hall; 1989.

33. Grambsch $P$, Therneau T. Proportional hazards tests and diagnostics based on weighted residuals. Biometrika. 1994;81(3):515-26.

34. MacKenzie E, Morris J, Jurkovich G, Yasui Y, Cushing B, Burgess A, et al. Return to work following injury: The role of economic, social, and jobrelated factors. Am J Public Health. 1998;88(11):1630-7.

35. Fitzharris $M$, Bowman $D$, Ludlow K. Factors associated with return-to-work and health outcomes among survivors of road crashes in Victoria. Aust N Z J Public Health. 2010;34(2):153-9.

36. Gopinath B, Jagnoor J, Harris IA, Nicholas M, Casey P, Blyth F, et al. Prognostic indicators of social outcomes in persons who sustained an injury in a road traffic crash. Injury. 2015;46(5):909-17.

37. Broadbent E, Petrie KJ, Main J, Weinman J. The brief illness perception questionnaire. J Psychosom Res. 2006;60(6):631-7.

38. Iles RA, Davidson M, Taylor NF. Psychosocial predictors of failure to return to work in non-chronic non-specific low back pain: a systematic review. Occup Environ Med. 2008;65(8):507-17.

39. Busse JW, Bhandari M, Guyatt GH, Heels-Ansdell D, Kulkarni AV, Mandel S, et al. Development and validation of an instrument to predict functional recovery in tibial fracture patients: the Somatic Pre-Occupation and Coping (SPOC) questionnaire. J Orthop Trauma. 2012;26(6):370-8.

40. Bandura A. Self-efficacy. In: Ramachandran V, editor. Encyclopedia of human behavior. 4th ed. New York: Academic Press; 1994

41. Leventhal H, Nerenz D, Steele D. Illness representations and coping with health threats. In: Baum A, Taylor S, Singer J, editors. Handbook of Psychology and Health. IV. Hillsdale, New Jersey: Lawrence Erlbaum Associates; 1984. p. 219-52

42. Grant GM, O'Donnell ML, Spittal MJ, Creamer M, Studdert DM. Relationship Between Stressfulness of Claiming for Injury Compensation and Long-term Recovery: A Prospective Cohort Study. JAMA Psychiatry. 2014;71(4):446-53.

43. Casey P, Feyer A, Cameron I. Associations with legal representation in a compensation setting 12 months after injury. Injury. 2015.

44. Elbers NA, Hulst L, Cuijpers P, Akkermans AJ, Bruinvels DJ. Do compensation processes impair mental health? A meta-analysis. [Review]. Injury. 2013:44(5):674-83

45. Grant G, Studdert DM. Poisoned Chalice? A Critical Analysis of the Evidence Linking Personal Injury Compensation Processes with Adverse Health Outcomes. Melbourne University Law Review. 2009:33:865-85.

46. Australian Bureau of Statistics. 1383.0.55.001 - Measures of Australia's Progress: Summary Indicators, 2009. Canberra: Australian Bureau of Statistics; 2009. Available from: http://www.abs.gov.au/AUSSTATS/abs@.nsf/Lookup/ 1383.0.55.001Main+Features122009. Accessed Feb 2015.

47. Australian Bureau of Statistics. 6202.0 - Labour Force, Australia, Jan 2013. Canberra: Australian Bureau of Statistics; 2013. Available from: http://www.abs.gov.au/AUSSTATS/abs@.nsf/Lookup/6202.0Main+ Features1Jan\%202013?OpenDocument. Accessed Feb 2015.

48. Brouwer S, Franche RL, Hogg-Johnson S, Lee H, Krause N, Shaw WS. Returnto-work self-efficacy: development and validation of a scale in claimants with musculoskeletal disorders. J Occup Rehabil. 2011;21(2):244-58.

49. Dennis SM, Harris M, Lloyd J, Powell Davies G, Faruqi N, Zwar N. Do people with existing chronic conditions benefit from telephone coaching? A rapid review. Aust Health Rev. 2013;37(3):381-8.

50. Moss-Morris R, Humphrey K, Johnson MH, Petrie KJ. Patients' perceptions of their pain condition across a multidisciplinary pain management program: do they change and if so does it matter? Clin J Pain. 2007;23(7):558-64.

51. Iles RA, Taylor NF, Davidson M, O'Halloran P. An effective coaching intervention for people with low recovery expectations and low back pain: a content analysis. J Back Musculoskelet Rehabil. 2014;27(1):93-101.

52. Armstrong BG. Effect of measurement error on epidemiological studies of environmental and occupational exposures. Occup Environ Med. 1998;55(10):651-6

53. Waddell G, Burton A, Kendall N. Vocational Rehabilitation. What works, for whom, and when? Norwich2013. Available from: https://www.gov.uk/ government/uploads/system/uploads/attachment_data/file/209474/hwwbvocational-rehabilitation.pdf. Accessed May 2015.

\section{Submit your next manuscript to BioMed Central and we will help you at every step:}

- We accept pre-submission inquiries

- Our selector tool helps you to find the most relevant journal

- We provide round the clock customer support

- Convenient online submission

- Thorough peer review

- Inclusion in PubMed and all major indexing services

- Maximum visibility for your research

Submit your manuscript at www.biomedcentral.com/submit 